\title{
CONSENT AND DECEPTION
}

\author{
Robert Jubb
}

CCORDING TO what Tom Dougherty labels the "lenient view," it "is only a
minor wrong to deceive another person into sex by misleading him or her
about certain personal features such as natural hair colour, occupation, or romantic intentions." ${ }^{1}$ The lenient view sees such lies as sleazy and so morally unattractive, but a long way from deceiving someone into sex by successfully pretending to be his or her spouse, for example. Dougherty forcefully argues that this view, though most likely fairly widely held, is false. If we deceive someone about a feature of a sexual encounter we have with her or him she or he would be "all things considered unwilling to engage in" if she or he knew it had this feature, that sex is nonconsensual. ${ }^{2}$ Since having nonconsensual sex with someone is a serious wrong, for example frequently seen as the distinctive wrong of rape, deceiving someone into sex is seriously wrong. ${ }^{3}$ According to Dougherty, when you lie to me about one of my "deal-breakers" for sex, you wrong me in much the same way as we often think of rapists wronging their victims.

This conclusion may well be both shocking and disturbing to us. The levels of rape in our societies are already extremely disturbing. A uk Ministry of Justice survey for England and Wales, for example, suggests that nearly one hundred thousand working-age women are raped every year in England and Wales. ${ }^{4}$ That is a horrifying statistic. If Dougherty is correct, something at least in a similar moral category to rape is in all probability far more common. It would be hard, I think, not to be shocked and disturbed by that. Given that his argument's conclusion is in that way difficult to bear, it seems to me that Dougherty's argument should itself be pressed upon pretty hard. If we accept it, however honest our own sex-

1 Dougherty, “Sex, Lies, and Consent," 718.

2 Dougherty, “Sex, Lies, and Consent," 719.

3 Dougherty himself does not take a position on whether rape should be defined as nonconsensual sex, although he notes that many do define it in that way ("Sex, Lies, and Consent," $721)$.

4 See uk Ministry of Justice, Home Office, and the Office for National Statistics, An Overview of Sexual Offending in England and Wales, 6. 
ual advances have been, we will have to understand our societies as even greater sites of wrongdoing than we already know them to be. Our relations to them and consequently to each other would have to become even more fraught and difficult. That is not a trivial cost, and not one we should bear without good reason.

There is also a broader issue here. Dougherty supports his conclusion about the wrongness of sexual deception with claims about how deception relates to permissions given by others more generally. His more general claim is that where we need another's permission to rightfully do something, we do it wrongly if we get that permission by deceiving her or him. In that sense, Dougherty's view is one that sees insincerity as almost always a deeply corrupting feature of human life. Concealing one's religious beliefs or lack of them from one's family so as to avoid arguments is, for Dougherty, a serious wrong because it involves deceiving people in continuing a relationship that does not have the character they want it to have. They are not obliged to continue inviting us round for family occasions, and if they knew how often we really attend religious services, they would not. We receive invitations from them by deception, and so on Dougherty's view, we are wronging them. That view seems to me much too moralistic about insincerity, condemning what appear to be central mechanisms of smoothing normal human interaction. Our idiosyncrasies and different commitments can quite easily come into conflict and shock each other, and without a way of concealing them, all kinds of valuable relationships would be much more difficult and much rarer. It is not only because of its implications about our sexual behaviour that I want to challenge Dougherty's argument then. Because of how it supports its central claim, it has further implications well beyond sexual ethics, and in many ways, those are even more concerning.

Dougherty attacks the lenient view in two related ways. First, he argues that it lacks the resources to distinguish different kinds of sexual deceptions before moving on to connect that failing with a broader view about the morality of consent and deception. I begin by trying to show that there are resources unrelated to the morality of sex to distinguish between different sexual deceptions and then move to argue that deception does not always undermine consent.

Let us begin with the distinctions between different kinds of sexual deceptions Dougherty claims are problematic for the lenient view. For example, few would deny that when D'Artagnan successfully pretends to be Milady's lover in order to have sex with her in The Three Musketeers, he seriously wrongs her. ${ }^{5}$ Dougherty then asks what distinguishes D'Artagnan's deception of Milady and deceptions of the sort the lenient view sees as less serious. ${ }^{6}$ If we cannot distin-

5 Dougherty, “Sex, Lies, and Consent," 724.

6 Dougherty, “Sex, Lies, and Consent," 728. 
guish D'Artagnan's deception from that of someone who laughs at jokes he or she does not find funny to get someone else into bed, then we must admit that the two cases are alike. Since it is difficult to claim that there is nothing seriously wrong with pretending to be someone's lover into order to deceive her or him into sex, not being able to distinguish that case from apparently more trivial ones suggests that they are in fact not so trivial.

Dougherty argues that the lenient view typically relies on an unacknowledged implausible and illiberally moralistic view of sex, and that once we give up that view, it is not clear on what basis the lenient view distinguishes seemingly trivial sexual deceptions from ones it acknowledges are more serious. As he puts it, "the Lenient Thesis can only plausibly be based on [an] account of consent that makes a fundamental distinction between different features of a sexual en-

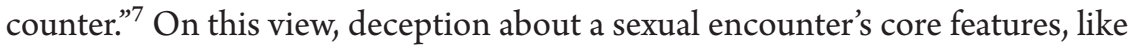
whom it is actually with, makes it nonconsensual whereas deception about its peripheral features, like what the person it is with finds funny, does not. One way to defend the lenient view then is to explain why an example of seriously wrongful sexual deception is seriously wrongful without using such a distinction between consent to different features of a sexual encounter, so showing that it may not need it. The only alternative explanation for the serious wrongfulness of sexual deception like D'Artagnan's of Milady that Dougherty considers is that it is harmful, which he persuasively argues is inadequate. ${ }^{8}$

However, the serious wrongfulness of D'Artagnan's deception of Milady can be explained in other ways. That deceit seems like it may well be wrong in at least three ways that do not depend on the morality of consent to sex or on its harmfulness. ${ }^{9}$ First, whether D'Artagnan lacks consent for sex with Milady, he wrongs both her and her lover by pretending to be him. Pretending to be someone with whom anyone is intimate is wrong because of the risk of corrupting or damaging their relationship, especially if the pretence is exploited for some kind of intimacy. It would be wrong for D'Artagnan to pretend to be Milady's father or brother, and even more so if he used that deception to discover secrets from her childhood, for instance. Second, D'Artagnan relies on the exclusivity of

7 Dougherty, “Sex, Lies, and Consent," 728.

8 Dougherty, "Sex, Lies, and Consent," 725-27.

9 Note that this defence of the lenient view against Dougherty's inference to the best explanation of this case is not committed to these features being sufficient to explain either the wrongfulness of D'Artagnan's deception or even the difference between that deception and deceptions the lenient view sees differently. Dougherty needs there to be nothing to explain the difference other than a moralized view of sexual consent. If there is something more than a moralized view of sexual consent, then there is an alternative explanation for the distinction the lenient view draws. 
Milady's sexual relationship with her lover to undermine that relationship by destroying its exclusivity. Exploiting the vulnerability created by the central feature of a person's commitment in that way is particularly cruel. Someone who seriously damages an athlete's ability by goading them to push her- or himself too hard wrongs him or her. Third and relatedly, D’Artagnan causes Milady to fail to keep a promise to her lover not to have sex with anyone else. Tempting someone into not going to see the aging and sick relative she or he has promised to visit is wrong, for example. The more weighty the promise, the more serious the wrong, and promises of sexual fidelity are typically fairly weighty.

There are then at least sometimes the resources to explain what is seriously wrong with obviously objectionable sexual deception without claiming that sexual deception itself is automatically seriously wrong. The lenient view can be defended in ways that Dougherty does not discuss. The wrongfulness of deceit does not always relate only to the way it invalidates a particular act of consent it makes possible, as Dougherty's explanation of the wrong of sexual deceit requires. However, Dougherty does not merely assume that the lenient view distinguishes apparently trivial sexual deception from cases like D'Artagnan's by distinguishing between forms of consent. As well as arguing that the lack of consent explains the seriousness of sexual deceptions like D’Artagnan's and that they cannot be distinguished from the deceptions the lenient view treats as trivial, Dougherty also argues that all nonconsensual sex is seriously wrong. ${ }^{10}$ If that argument holds, then the distinction the lenient view relies on must be one relating to consent. Otherwise, in virtue of being nonconsensual, sex must be seriously wrong. Either deception does not undermine consent, or the absence of consent to sex does not necessarily make it seriously wrong. Accepting the explanation I have just given of why D'Artagnan's deception of Milady is seriously wrong then requires accepting one of two burdens. Anyone accepting it must either accept that nonconsensual sex is not automatically seriously wrong or explain why deception does not always undermine consent. It is only if one of those two horns is grasped that the explanation can do the work its defence of the lenient view needs it to, and show that D'Artagnan's deception is not like pretending to find someone's jokes funny so that she or he will have sex with you. Otherwise, pretending to find someone's jokes funny so that he or she will have sex with you makes that sex nonconsensual and, in virtue of being nonconsensual, seriously wrong.

This is where Dougherty's view about the morality of sexual deception begins to link with his views about the morality of deception in general. The link is through a dilemma Dougherty's view faces parallel to that which confronts any-

10 See, for example, Dougherty, "Sex, Lies, and Consent," 720. 
one defending the lenient view. On the one hand, if Dougherty adopts a comparatively demanding view of consent, then deception will undermine consent, but it will be less clear that full consent is necessary to grant permissions. It will then be harder to maintain that all nonconsensual sex is seriously wrong since it will seem like something less demanding than full consent is enough for permission for sex. On the other hand, if Dougherty adopts a comparatively lax view of consent, then although it will seem like consent is the standard mechanism for giving permissions to act, it will be compatible with deception. Deceptive sex will then sometimes still be consensual sex. Dougherty typically resolves this dilemma by opting for a comparatively demanding view of consent. Insofar as he outlines his view, it requires that agreement is or at least would be given to any eventualities covered by the consent. ${ }^{11}$ If deception occurs about what Dougherty calls a deal-breaker, a feature of whatever is consented to whose absence or presence is required for consent, consent has not been given.

Dougherty's view seems overly demanding about the role agreement over details plays in consent. Imagine a landlord who demands that tenants sing in the shower every morning. I do not think that tenants who lie about whether they will sing in order to rent the property are in some way wronging the landlord, even though the landlord could refuse to rent them the property if they did not promise to sing. ${ }^{12}$ Equally, imagine a tenant who will only rent properties that have never been lived in by children. I do not see anything seriously wrong with a landlord lying about this. At least if either of these deceptions is wrong, it is not wrong in the way that many nonconsensual bargains are. They are certainly not wrong in the way that deceiving someone about whether you in fact own a property or can pay the rent are, typically independently of whether that deception ends up harming its victim.

That suggests that deception about a deal-breaker is not always as important as Dougherty thinks. One form of resistance to that suggestion would be to deny that the relevant standards for the wrongfulness of deceptions can be transferred from agreements over property to agreements over sexual contact. However, Dougherty is not in a position to distinguish between consent to those two different kinds of agreements. He rejects the moralism about sexual consent associated with the lenient view. Equally, his examples suggest that he sees our

11 See, for example, "Sex, Lies, and Consent," 719.

12 This is important, since it suggests that this is not a case in which the landlord is subject to a nondiscrimination requirement. If she or he were subject to a nondiscrimination requirement, he or she would have no right to require singing and so there would be no need to gain permission. It might also not be analogous to choices over sexual partners, where at least it seems more likely to be permissible to discriminate on grounds of race, religion, gender, and other grounds standardly protected by nondiscrimination requirements. 
rights over property as similar in this way to our rights over our bodies. ${ }^{13}$ At the level of generality with which Dougherty is concerned, interests in controlling our property often seem similar to interests in the sexual autonomy Dougherty sees as underlying his rejection of the lenient view. ${ }^{14}$ In general, people have an interest in being able to use their property as they please, and we tend to abjure moralistic judgments on how they use it just as Dougherty urges that we abjure moralistic judgments about people's sex lives. Yet it seems we are prepared to allow for deception in the rental market, and do not judge all deceptions alike, even though some deceptions are very serious. Why not also allow deception when we are choosing whom to have sex with, or at least distinguish different kinds of deception?

The kinds of deception we allow in the rental market seem to relate to the interests we think people typically have in renting property. This might seem a form of moralism about how we use property of the sort Dougherty condemns about sexual consent, but it does not have to be. When we decide what lies are permissible in the rental market, we consider what kind of impact allowing them would have on interests whose value is established independently of the existence of the rental market. We have interests, for example, in having a private space in which we are able to act as we please without needing permission from others. This explains why we think tenants may lie to their landlord about whether they are singing in the shower and, perhaps, given that interest extends to setting terms on how others use our property, why the landlord may insist that they do sing in the shower. This interest though is not dependent on views about how we use property. It depends instead on a view about the value of privacy. It is compatible with individuals voluntarily giving up that privacy, for example.

Similarly, the deceptions we think are acceptable when we seek sexual partners, I suggest, are deceptions that relate to the interests we typically think are at stake in how and whether we seek sexual partners. Obvious candidates for those interests include satisfying physical desire, securing a sense of esteem, achieving a kind of intimacy and forming lasting emotional bonds. In particular, being transparent will often be in tension with securing a sense of esteem, since others are not likely to value everything that we do or have done. Especially when we may also be vulnerable because of our intimacy, a little dishonesty may well be warranted. Intimacy may be unattainable without insincerity in some circumstances precisely because of our wariness about the vulnerability it involves. The

See Dougherty, "Sex, Lies, and Consent," 732-34, 737-39.

14 See for example, Dougherty, "Sex, Lies, and Consent," 730, on which Dougherty insists that "it is up to each individual to determine which features of a sexual encounter are particularly important to her." 
value of these interests is not dependent on a particular view about what sex is for, nor will they only be at stake in our seeking of sexual partners if we adopt a particular view about what sex is for. We cannot choose how we or our sexual partners respond to our sexual encounters, and we may reasonably want to secure ourselves against certain kinds of response.

Of course, this is not a full defence of the lenient view. Insofar as it is a standard and widely held view about an area of life that Dougherty rightly points out contained in the recent past a great deal of injustice, it is very likely that the lenient view is not fully defensible. ${ }^{15}$ We have good reason to think that we have not begun to identify all the injustices that mar our sexual lives. As I have already pointed out, we are certainly a very long way from eradicating them. However, it does seem like some of what the lenient view excuses ought to be excused. There are grounds for thinking that not all sexual deceptions are similarly seriously wrong. We can give reasons that do not relate to consent why some sexual deception is seriously wrong, and it seems like we might often have legitimate interests in deceiving sexual partners. Indeed, many of the interests at stake in deceiving sexual partners are also threatened by many other forms of human interaction, which often cannot be straightforwardly separated from attempts to seek sexual partners anyway. This is why it is permissible to deceive relatives, colleagues, friends, and people you do business with, as well as total strangers, about your religious affiliation or lack of it, your political views, your job, your sexual preferences, and so on. They do not always need to know the whole truth in order for your relationships with them not to be exploitative and so wrongful and, for many of the same reasons, nor do your sexual partners. ${ }^{16}$

University of Reading r.s.d.jubb@reading.ac.uk

\section{REFERENCES}

Dougherty, Tom. "Sex, Lies, and Consent." Ethics 123, no. 4 (July 2013): 717-44. uk Ministry of Justice, Home Office, and Office for National Statistics. An Overview of Sexual Offending in England and Wales. January 10, 2013. https:// www.gov.uk/government/statistics/an-overview-of-sexual-offending-in-en gland-and-wales.

15 See Dougherty, "Sex, Lies, and Consent," 722.

16 I would like to thank Tom Dougherty, Hugh Lazenby, Patrick Tomlin, and Maria Carla Zizolfi for comments on earlier versions of this piece, as well as an anonymous referee. 